\title{
Clinical and imaging characteristics in patients undergoing surgery for lumbar epidural lipomatosis
}

Taketoshi Yasuda $^{1 *}$, Kayo Suzuki ${ }^{1 \dagger}$, Yoshiharu Kawaguchi ${ }^{1}$, Shoji Seki ${ }^{1}$, Hiroto Makino ${ }^{1}$, Kenta Watanabe ${ }^{1}$, Takeshi Hori ${ }^{2}$, Tohru Yamagami ${ }^{3}$, Masahiko Kanamori ${ }^{4}$ and Tomoatsu Kimura ${ }^{1}$

\begin{abstract}
Background: Lumbar epidural lipomatosis (LEL) is characterized by abnormal accumulation of unencapsulated adipose tissue in the spinal epidural space. Such accumulation compresses the dural sac and nerve roots, and results in various neurological findings. However, the pathophysiology of LEL remains unclear. This study examined the associations between imaging and clinical findings in detail, and investigated the mechanisms underlying symptom onset by measuring intraoperative epidural pressures in LEL.

Methods: Sixteen patients (all men; mean age, 68.8 years) were enrolled between 2011 and 2015. Mean body mass index was $26.5 \mathrm{~kg} / \mathrm{m}^{2}$. Four cases were steroid-induced, and the remaining 12 cases were idiopathic. All patients presented with neurological deficits in the lower extremities. Cauda equina syndrome (CES) alone was seen in 8 patients, radiculopathy alone in 4, and both radiculopathy and CES (mixed CES) in 4. All patients subsequently underwent laminectomy with epidural lipomatosis resection and were followed-up for more than 1 year. We investigated the clinical course and imaging and measured epidural pressures during surgery.
\end{abstract}

Results: Subjective symptoms improved within 1 week after surgery. Mean Japanese Orthopaedic Association (JOA) score was $15.2 \pm 2.8$ before surgery, improving to $25.4 \pm 2.5$ at 1 year after surgery. On magnetic resonance imaging, all lipomatosis lesions included the L4-5 level. On preoperative computed tomography, saucerization of the laminae was not observed in radiculopathy cases, whereas saucerization of the posterior vertebral body was observed in all radiculopathy or mixed CES cases. Intraoperative epidural pressures were significantly higher than preoperative subarachnoid pressures. The results suggest that high epidural pressure resulting from the proliferation of adipose tissue leads to saucerization of the lumbar spine and subsequent symptoms.

Conclusions: Clinical courses were satisfactory after laminectomy. In LEL, epidural pressure increases and symptoms develop through the abnormal proliferation of adipose tissue. Higher epidural pressures induce saucerization of the laminae and/or posterior vertebral body. Furthermore, the direction of proliferative adipose tissue (i.e., site of saucerization) might be related to the types of neurological symptoms.

Keywords: Lumbar epidural lipomatosis, Clinical feature, Japanese Orthopaedic Association score, Laminectomy, Epidural space pressure, Computed tomography, Magnetic resonance imaging, Saucerization, Adipose tissue, Body mass index

* Correspondence: yasuda@med.u-toyama.ac.jp

${ }^{\dagger}$ Equal contributors

${ }^{1}$ Department of Orthopaedic Surgery, Faculty of Medicine, University of

Toyama, 2630 Sugitani, Toyama, Toyama 930-0194, Japan

Full list of author information is available at the end of the article

(c) The Author(s). 2018 Open Access This article is distributed under the terms of the Creative Commons Attribution 4.0 International License (http//creativecommons.org/licenses/by/4.0/), which permits unrestricted use, distribution, and reproduction in any medium, provided you give appropriate credit to the original author(s) and the source, provide a link to the Creative Commons license, and indicate if changes were made. The Creative Commons Public Domain Dedication waiver (http://creativecommons.org/publicdomain/zero/1.0/) applies to the data made available in this article, unless otherwise stated. 


\section{Background}

Spinal epidural lipomatosis (SEL) is a rare condition that was first described by Lee et al. in 1975 [1]. SEL is defined as the abnormal accumulation of unencapsulated adipose tissue in the spinal epidural space, and causes various neurological symptoms [2]. Secondary SEL occurs in relation to exogenous steroid treatment $[2,3]$, endocrinopathies such as Cushing syndrome [4], and hypothyroidism [5]. Idiopathic SEL may occur without any history of steroid use or endocrine disorder $[6,7]$. The condition predominantly affects males, and more than $75 \%$ of all reported patients are obese [8-10]. However, factors involved in the onset of SEL remain unclear.

Criteria for clinical symptoms and imaging characteristics of SEL have not been firmly established. The neurological symptoms resemble degenerative lumbar spinal stenosis (LSS). Patients with LSS have recently been reported to show increased epidural pressure at the level of stenosis [11]. However, no reports have provided values for epidural pressure in the spinal canal of SEL patients. Generally, adipose tissue is soft, and is unlikely to provide substantial compression on the dural sac or nerve root. We therefore hypothesized that abnormal proliferation of adipose tissue within the spinal canal increases the epidural pressure and leads to symptoms in SEL.

Diagnosis of SEL is mainly based on the results of magnetic resonance imaging (MRI), which is considered the most sensitive modality for assessing adipose tissue $[12,13]$. In the majority of cases, excessive deposition of epidural fat (EF) showing signal hyperintensity on T1weighted imaging and intermediate signal intensity on T2-weighted imaging is found in the spinal epidural space [12]. A characteristic "Y-sign" or square stellate dural sac on axial MRI is often seen in lumbar epidural lipomatosis (LEL) [14]. Myelography and postmyelography computed tomography (CT) have also been applied for diagnostic purposes, but are not as sensitive as MRI $[14,15]$. Myelography and CT myelography thus do not allow clear differentiation between LSS and LEL. However, few reports have described detailed imaging findings from MRI and CT for a large number of cases. Furthermore, no reports have clarified the relationship between image findings and symptoms. The purpose of this study was to examine imaging characteristics and measure epidural pressures in patients with LEL undergoing decompressive surgery. This study suggests that high epidural pressure resulting from the proliferation of adipose tissue leads to saucerization of the lumbar spine and subsequent symptoms.

\section{Methods}

Sixteen patients underwent decompressive surgery for LEL in our institution between 2011 and 2015. The indication for surgery was neurogenic symptoms that failed to respond to conservative treatment for more than 3 months. We diagnosed LEL of more than grade II by Borré's definition at the axial plane parallel to the superior end plate of the S1 vertebral body on T1-weighted axial MRI [12]. Briefly, Grade II represents moderate overgrowth of EF, defined as having an EF/spinal anteroposterior diameter (SpiC) index more than $50 \%$ at the spinal level responsible for symptoms. In contrast, cases with EF/SpiC index less than 50\% were excluded. MRI was assessed by 2 different spine surgeons (T.Y. and K.S.). Furthermore, we excluded subjects who were treated with reduction operation of spinal deformities such as degenerative scoliosis with a Cobb angle more than 10 degrees; lumbar kyphosis with a Cobb angle more than 10 degrees, and spondylolisthesis with a Meyerding classification grade higher than 1 [16]. Demographic data are shown in Table 1. Slight LSS was recognized in some cases (Cases 3, 10, 12, 15, and 16), but severe degenerative LSS, in which epidural adipose tissue was absent at the level of the intervertebral disc and the dural sac was compressed, were excluded. Cases in which a herniated disc was excised were also excluded. Mean age was 68.8 years (range, 47-77 years) at the time of surgery. Four patients had a history of steroid administration and 12 patients had no history of steroid administration or endocrinopathies. Mean body mass index (BMI) was $26.2 \mathrm{~kg} / \mathrm{m}^{2}$ (range, 25.2$27.7 \mathrm{~kg} / \mathrm{m}^{2}$ ). All patients presented with neurological deficits in the lower extremities with intermittent claudication, as seen in cauda equina syndrome (CES) and/or radiculopathy (Table 2). Neural symptoms were classified into 3 types according to a previous report [17]: radicular type, presenting as unilateral radicular pain; cauda equina type, showing symptoms with less dermatomal-specific neurogenic claudication; and mixed type, showing characteristics of both radicular and cauda equine types. All patients subsequently underwent trumpet laminectomy [18] with epidural lipomatosis resection. Patients were followedup for more than 1 year. The present study was approved by the ethics committee at Toyama University Hospital. Patients provided written informed consent to participate in this analysis.

\section{Clinical evaluation}

We investigated the duration of subjective symptoms, levels of neural disorder, and types of neural disorders before surgery. Furthermore, the relationship between the symptomatic level and the most severely stenotic level on MRI was analyzed.

Clinical courses were evaluated using the Japanese Orthopaedic Association (JOA) scores at 3 months, 6 months, and 1 year after surgery (Table 3) [19]. Briefly, subjective symptoms ( 9 points: low back pain, leg pain, 
Table 1 Profiles of patients with lumbar epidural lipomatosis

\begin{tabular}{lllll}
\hline Case & Age (years) & Medical history & History of steroid administration & BMl $\left(\mathrm{kg} / \mathrm{m}^{2}\right)$ \\
\hline 1 & $64-65$ & none & none & 26.1 \\
2 & $79-80$ & gout & none & 26.2 \\
3 & $77-78$ & none & none & 27.1 \\
4 & $69-70$ & none & none & 26.5 \\
5 & $70-71$ & prostatic hypertrophy & none & 25.6 \\
6 & $73-74$ & none & none & 25.8 \\
7 & $77-78$ & hypertension & none & 26.6 \\
8 & $69-70$ & none & none & 26.9 \\
9 & $47-48$ & none & none & 27.7 \\
10 & $73-74$ & none & none & 25.2 \\
11 & $69-70$ & none & none & 25.8 \\
12 & $61-62$ & none & none & 25.8 \\
13 & $70-71$ & sudden deafness & PSL 5 mg/day for 1 year & 25.5 \\
14 & $77-78$ & polymyalgia rheumatica & PSL 7.5 mg/day for 3 years & 26.2 \\
16 & $62-63$ & interstitial pneumonia & PSL 8 mg/day for 1 year & 27.6 \\
Mean & $64-65$ & Behçet disease & PSL 8 mg/day for 12 years &
\end{tabular}

All patients are men. BMI body mass index, PSL prednisolone

and walking ability), clinical signs (6 points: sensory and motor disturbance and positive straight leg raise test results), and activities of daily living (ADL, 14 points) were evaluated. The ratio of recovery, which indicates the degree of normalization after surgery, was calculated using the following formula: (postoperative score - preoperative score) $\times 100 /$ [29 (full score) - preoperative score] [20]

\section{Imaging analysis}

\section{Magnetic resonance imaging}

In all 16 cases, MRI was performed within 1 month before surgery. In cases whose symptoms persisted more than 6 months, MRI was re-examined, but there was no major change. We evaluated the most severely stenotic level, LEL level and grade, and shape of the dural sac on

Table 2 Patients' clinical data

\begin{tabular}{|c|c|c|c|c|c|}
\hline Case & LEL levels & LEL grade & Duration of symptoms (months) & Level (s) of neural disorder & Type of neural disorder \\
\hline 1 & $\mathrm{~L} 2-\mathrm{S} 1$ & 3 & 8 & L5 & Cauda equina \\
\hline 2 & $\mathrm{~L} 2-\mathrm{S} 1$ & 3 & 48 & L3 & Cauda equina \\
\hline 3 & L3-S1 & 3 & 5 & $\mathrm{~L} 5, \mathrm{~S} 1$ & Radicular \\
\hline 4 & L3-S1 & 2 & 36 & $\llcorner 4$ & Cauda equina \\
\hline 5 & L3-S1 & 2 & 24 & $\mathrm{~L} 5, \mathrm{~S} 1$ & Radicular \\
\hline 6 & $\mathrm{~L} 2-\mathrm{S} 1$ & 3 & 10 & L4 & Cauda equina \\
\hline 7 & $\llcorner 3-5$ & 2 & 4 & L5 & Mixed \\
\hline 8 & $\llcorner 4-S 1$ & 3 & 6 & $\llcorner 4$ & Cauda equina \\
\hline 9 & $\llcorner 2-5$ & 3 & 6 & L3 & Radicular \\
\hline 10 & $\mathrm{~L} 2-5$ & 2 & 3 & L4 & Radicular \\
\hline 11 & $\llcorner 3-5$ & 2 & 15 & $\llcorner 4$ & Mixed \\
\hline 12 & L2-S1 & 2 & 10 & $\llcorner 4$ & Cauda equina \\
\hline 13 & L2-S1 & 3 & 9 & L5 & Mixed \\
\hline 14 & L3-S1 & 3 & 5 & $\llcorner 4$ & Cauda equina \\
\hline 15 & L3-S1 & 2 & 3 & L4 & Cauda equina \\
\hline 16 & L3-5 & 2 & 8 & $\llcorner 4$ & Mixed \\
\hline
\end{tabular}

LEL lumbar epidural lipomatosis, $L$ lumbar, $S$ sacral 
Table 3 Scoring system for the treatment of low back disorders devised by the Japanese Orthopaedic Association

\begin{tabular}{|c|c|c|c|}
\hline Item & \multicolumn{3}{|l|}{ Score } \\
\hline \multicolumn{4}{|l|}{ Subjective symptoms } \\
\hline \multicolumn{4}{|l|}{ Low back pain } \\
\hline None & \multicolumn{3}{|l|}{3} \\
\hline Occasional mild pain & \multicolumn{3}{|l|}{2} \\
\hline Frequent mild or occasional severe pain & \multicolumn{3}{|l|}{1} \\
\hline Frequent severe pain & \multicolumn{3}{|l|}{0} \\
\hline \multicolumn{4}{|l|}{ Leg pain and/or numbness } \\
\hline None & \multicolumn{3}{|l|}{3} \\
\hline Occasional mild leg pain and/or numbness & \multicolumn{3}{|l|}{2} \\
\hline $\begin{array}{l}\text { Frequent mild or occasional severe leg } \\
\text { pain and/or numbness }\end{array}$ & \multicolumn{3}{|l|}{1} \\
\hline $\begin{array}{l}\text { Frequent severe leg pain and/or } \\
\text { numbness }\end{array}$ & \multicolumn{3}{|l|}{0} \\
\hline \multicolumn{4}{|l|}{ Walking capacity } \\
\hline Normal & \multicolumn{3}{|l|}{3} \\
\hline $\begin{array}{l}\text { Able to walk > } 500 \mathrm{~m} \text { with leg pain } \\
\text { and/or numbness }\end{array}$ & \multicolumn{3}{|l|}{2} \\
\hline $\begin{array}{l}\text { Able to walk } 100-500 \mathrm{~m} \text { with leg pain } \\
\text { and/or numbness }\end{array}$ & \multicolumn{3}{|l|}{1} \\
\hline $\begin{array}{l}\text { Able to walk }<100-500 \mathrm{~m} \text { with leg } \\
\text { pain and/or numbness }\end{array}$ & \multicolumn{3}{|l|}{0} \\
\hline \multicolumn{4}{|l|}{ Clinical signs } \\
\hline \multicolumn{4}{|l|}{ Straight leg raise test } \\
\hline Normal & \multicolumn{3}{|l|}{2} \\
\hline 30 degrees to 70 degrees & \multicolumn{3}{|l|}{1} \\
\hline$<30$ degrees & \multicolumn{3}{|l|}{0} \\
\hline \multicolumn{4}{|l|}{ Motor function } \\
\hline Normal & \multicolumn{3}{|l|}{2} \\
\hline Slight weakness (MMT: good) & \multicolumn{3}{|l|}{1} \\
\hline Severe weakness (MMT: poor) & \multicolumn{3}{|l|}{0} \\
\hline \multicolumn{4}{|l|}{ Sensory function } \\
\hline Normal & \multicolumn{3}{|l|}{2} \\
\hline Slight disturbance & 1 & & \\
\hline Severe disturbance & 0 & & \\
\hline Bladder function & & & \\
\hline Normal & 0 & & \\
\hline Mild dysuria & -3 & & \\
\hline Severe dysuria & -6 & & \\
\hline Restriction of activities of daily living & Impossible & Difficult & Easy \\
\hline Turning in bed & 0 & 1 & 2 \\
\hline Standing up & 0 & 1 & 2 \\
\hline Washing face & 0 & 1 & 2 \\
\hline Half-sitting posture & 0 & 1 & 2 \\
\hline
\end{tabular}

Table 3 Scoring system for the treatment of low back disorders devised by the Japanese Orthopaedic Association (Continued)

\begin{tabular}{llll}
\hline Item & Score & \\
\hline Sitting & 0 & 1 & 2 \\
Lifting & 0 & 1 & 2 \\
$\quad$ Running & 0 & 1 & 2 \\
Total for normal & 29 & & \\
\hline MMT manual muscle testing & &
\end{tabular}

the latest MRI. LEL grade was classified based on midsagittal T1-weighted MRI (MAGNETOM Avanto; Siemens, München, Germany) under a magnetostatic field intensity of $1.5 \mathrm{~T}$ [12]. Shape of the dural sac was divided into 3 types: circular; square stellate; or "Y-sign" at the level of each intervertebral disc and middle of the vertebral body in which LEL was present on T1weighted axial MRI, according to a previous report (Fig. 1) [12].

\section{Computed tomography}

In 13 cases, myelography and $\mathrm{CT}$ myelography were performed before surgery within 1 week. We evaluated the presence of saucerization of the laminae or/and posterior vertebral body. Saucerization of the laminae was defined as a dome-formed spinal canal with thinness of the vertebral lamina at the level of each involved intervertebral disc on axial view (Fig. 2). Saucerization of the posterior vertebral body was defined as a finding of compression more than $2 \mathrm{~mm}$ compared to usual for the posterior vertebral body in the reconstructed sagittal view (Fig. 3). CT findings were assessed by two different spine surgeons (T.Y. and K.S.).

\section{Preoperative subarachnoid pressure and intraoperative epidural pressure}

Preoperatively, subarachnoid pressures were measured at the L2 - 3 level during myelography. Measurement was performed with patients in the left decubitus position.

We measured intraoperative epidural pressure at L4-5, as previously described [11]. Briefly, surgery was performed with patients in the prone position, using a standard posterior midline approach. Prior to the actual surgical intervention, an arterial line (A-line) catheter was first calibrated in accordance with the instructions from the manufacturer, then inserted through an interlaminar window at the L4-5 level. Complete flavectomy had not been performed at this point to allow correct measurement of pressure. Because pressure values during positioning of the catheter fluctuate considerably due to mechanical loading at the tip of the catheter, measurements were taken after a time lag of $10 \mathrm{~s}$ after positioning of the catheter. Pressure values were recorded at half the height of the vertebral body. Measurements were 


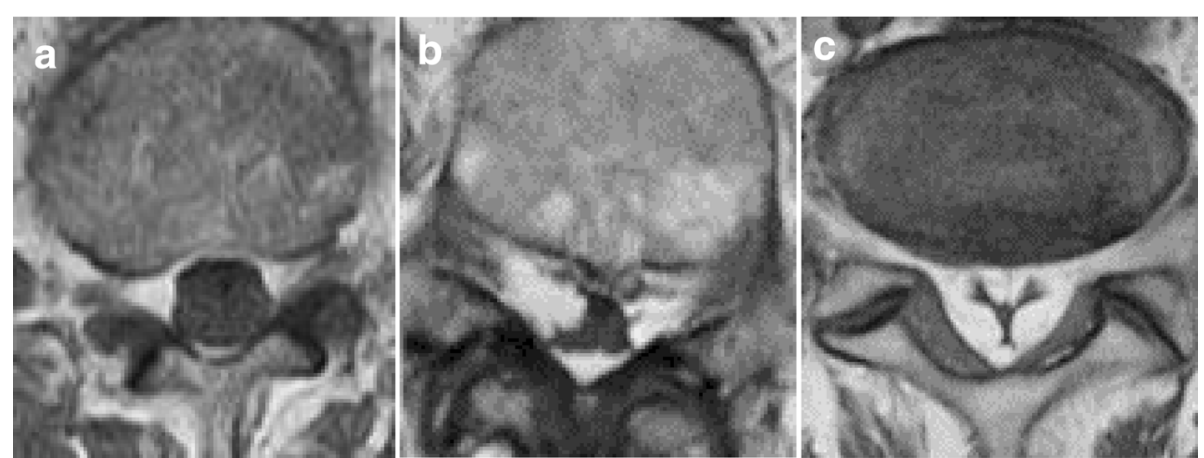

Fig. 1 Classification of shape of dural sac on axial T1-weighted magnetic resonance imaging. a Circular type, b square stellate type, c "Y-sign"

performed 3 times, and the average of the 3 measurements was calculated. Patients provided written informed consent for intraoperative measurement of epidural pressure, which required an extension of the operating time by approximately $15 \mathrm{~min}$. We compared intraoperative epidural pressures to preoperative subarachnoid pressures.

\section{Statistical analysis}

Values are expressed as means \pm standard deviation (SD). Significant differences between means were analyzed using the Mann-Whitney's $U$ test, and a $P$ value less than 0.05 was considered statistically significant.

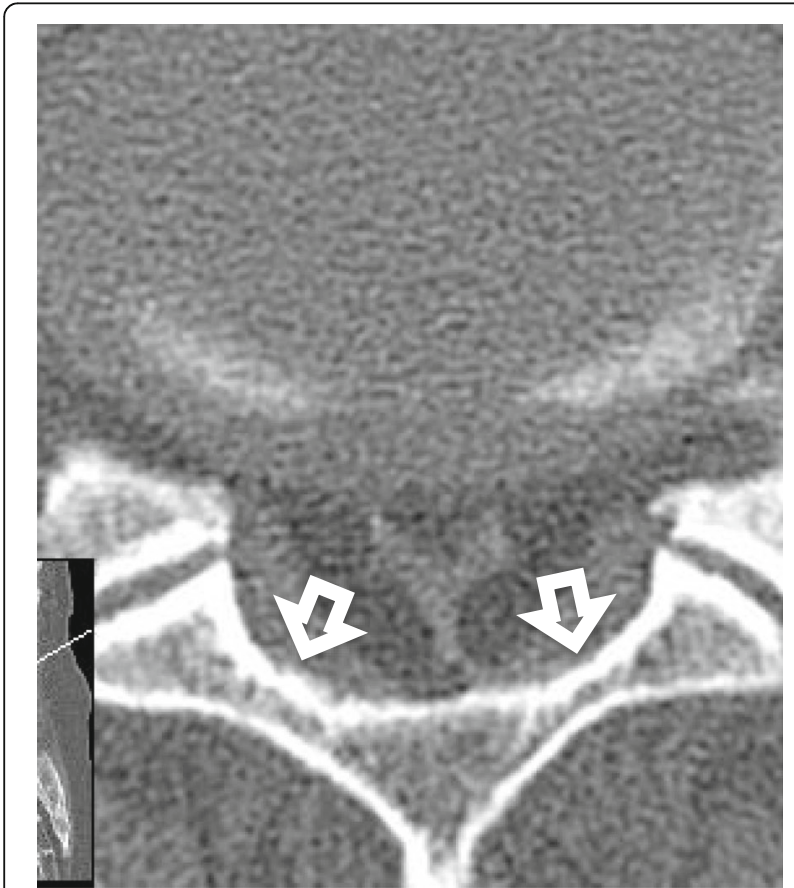

Fig. 2 Saucerization of laminae on computed tomography. Saucerization of laminae is defined as a dome-formed spinal canal with thinness of the vertebral lamina (arrows)

\section{Results}

Clinical evaluation

Preoperative symptoms

Mean duration of symptoms before surgery was 13.1 months (range, 3-48 months) (Table 2). Among the

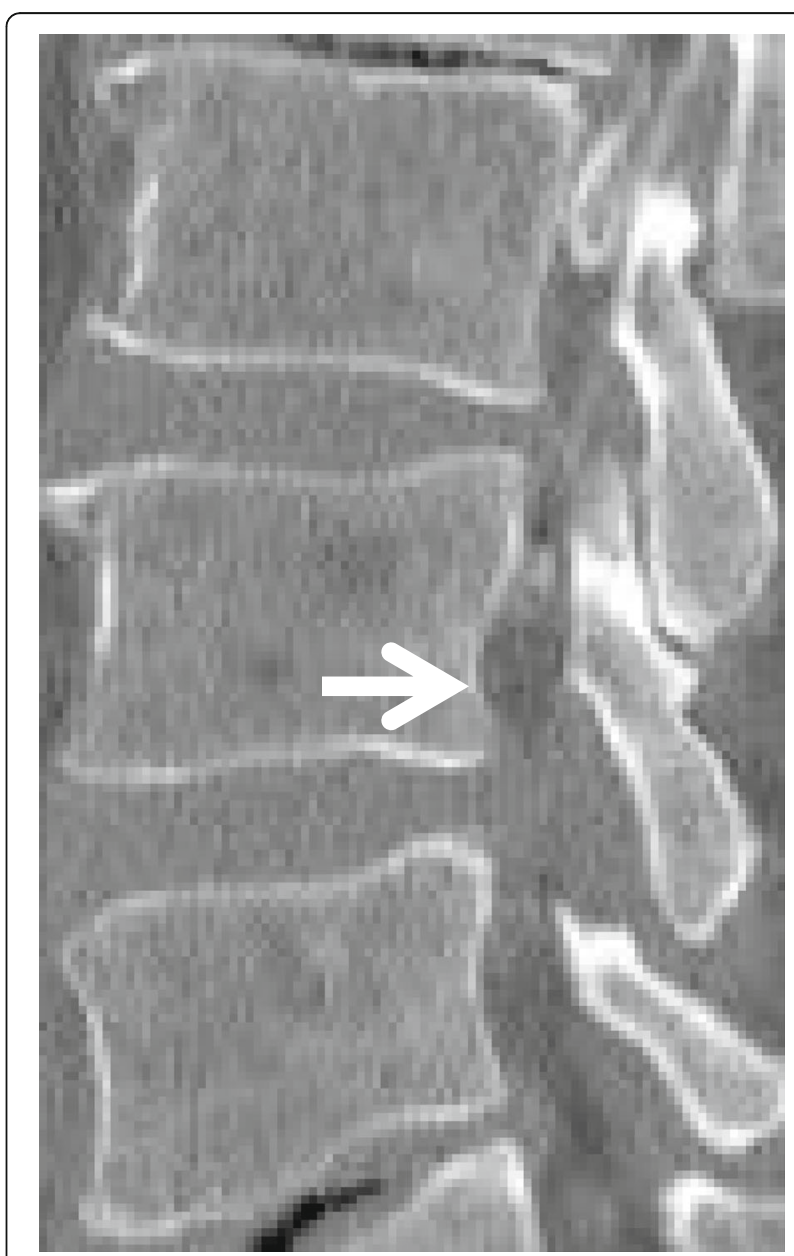

Fig. 3 Saucerization of posterior vertebral body on computed tomography $(\mathrm{CT})$. Saucerization of posterior vertebral body is defined findings of compression of more than $2 \mathrm{~mm}$ than the usual posterior body of a vertebra in the reconstructed sagittal CT view (arrow) 
16 patients, the level of neural disorder was L3 in 2 patients (13\%), L4 in 9 patients (56\%), and L5 and/or S1 in 5 patients $(31 \%)$. Types of neural disorder were categorized as cauda equina type in 8 patients (50\%), mixed type in $4(25 \%)$, and radicular type in 4 (25\%). In 12 patients $(75 \%)$, the level of neural disorder corresponded to the most stenotic level.

\section{Clinical course}

In all patients, subjective symptoms improved within 1 week after surgery. Mean JOA scores were $15.2 \pm 2.8$ preoperatively, $21.3 \pm 2.2$ at 3 months after surgery, $24.6 \pm$ 1.2 at 6 months, and $25.4 \pm 2.5$ at 1 year. The ratio of recovery at 1 year after surgery was $70.9 \pm 5.2 \%$. No recurrent and/or worsening cases were identified during follow-up.

\section{Imaging evaluation}

\section{Magnetic resonance imaging findings}

LEL existed from L2-S1 in 5 patients (31\%), L2-5 in 2 (13\%), L3-S1 in 5 (31\%), L3-5 in 3 (19\%), and L4$\mathrm{S} 1$ in $1(6 \%)$ (Table 4). All lipomatosis lesions included the L4-5 level. LEL was grade II in 8 patients (50\%) and grade III in $8(50 \%)$. Shapes of the dural sac are shown in Table 4. A square stellate shape was seen at the L4 and L4-5 levels, and the "Y-sign" was seen only at the L5-S level.

\section{Computed tomography findings}

Saucerization of the laminae was recognized in 14 of the 16 patients (88\%), at L3-4 in 3 patients (20\%), L4-5 in $12(75 \%)$ and L5-S1 in 10 (63\%), with some overlap of levels (Table 4). Saucerization of the posterior vertebral body was recognized in 6 patients (56\%), at the L4 level in all cases. With regard to the relationship between subjective symptoms and CT findings, the 2 patients in whom saucerization of the laminae was not seen had radiculopathy (Cases 3 and 9). Furthermore, symptoms of patients with saucerization of the posterior vertebral body were radicular or mixed type (Cases 1, 3, 5, 7, 9, 10 , and 11).

\section{Preoperative subarachnoid oressures and intraoperative epidural pressures}

Mean preoperative subarachnoid pressure (standard value: 7-18 $\mathrm{cmH}_{2} \mathrm{O}$ ) was $12.0 \pm 2.8 \mathrm{cmH}_{2} \mathrm{O}$, and mean intraoperative epidural pressure (standard value: -3 to 1 $\mathrm{cmH}_{2} \mathrm{O}$ ) was $42.9 \pm 14.8 \mathrm{cmH}_{2} \mathrm{O}$ (Table 5). Intraoperative epidural pressures were significantly higher than preoperative subarachnoid pressures (Student's $t$ test, $P<0.001)$. In patients with lipomatosis alone, mean preoperative subarachnoid pressure was $11.3 \pm 3.0 \mathrm{cmH}_{2} \mathrm{O}$ and mean intraoperative epidural pressure was $46.1 \pm$ $15.6 \mathrm{cmH}_{2} \mathrm{O}$. In patients with both slight LSS and LEL, mean preoperative subarachnoid pressure was $13.5 \pm 1.7$ $\mathrm{cmH}_{2} \mathrm{O}$ and mean intraoperative epidural pressure was $35.0 \pm 10.0 \mathrm{cmH}_{2} \mathrm{O}$. No significant difference was seen between patients with LEL alone and patients with both slight LSS and LEL.

\section{Illustrative case (case 15)}

A 62-year-old man was admitted to our hospital with bilateral leg pain. He had a 3-month history of intermittent low back pain accompanied by asymmetrical, slowly progressive bilateral leg pain. The neural disorder was diagnosed as L4 cauda equina type and the preoperative JOA score was 14 . The patient was slightly overweight, with a BMI of $27.6 \mathrm{~kg} / \mathrm{m}^{2}$. He had been receiving oral prednisolone at $8 \mathrm{mg} /$ day for interstitial pneumonia for 8 years. Lumbar radiography showed slight spondylosis. Lumbar MRI revealed moderate disc bulging at the L3L5 levels (Fig. 4). A high-intensity mass lesion on T1and T2-weighted imaging consistent with LEL was seen between L3 and S1. The mass extended both anteriorly and posteriorly and markedly compressed the dural sac with square stellate deformation of the dural sac at the L3-4 and L4-5 disc levels (Fig. 5a, b). The typical "Ysign" [18] was seen at the L5-S1 level (Fig. 5c), and MRI

Table 4 Magnetic resonance imaging (MRI) and computed tomography $(C T)$ findings

\begin{tabular}{|c|c|c|c|c|c|c|}
\hline \multirow[t]{2}{*}{ Level } & \multirow{2}{*}{$\begin{array}{l}\text { Number of } \\
\text { total cases }\end{array}$} & \multicolumn{3}{|c|}{ Shape of the dural sac on MRI } & \multicolumn{2}{|c|}{ Saucerization on $\mathrm{CT}$} \\
\hline & & Circular & Square stellate & "Y-sign" & laminae & Posterior vertebral body \\
\hline L2 & 7 & 6 & 1 & 0 & & 0 \\
\hline L2-3 & 7 & 6 & 1 & 0 & 0 & \\
\hline L3 & 15 & 10 & 5 & 0 & & 0 \\
\hline L3-4 & 15 & 9 & 6 & 0 & 3 & \\
\hline L4 & 16 & 5 & 10 & 0 & & 6 \\
\hline$\llcorner 4-5$ & 16 & 3 & 13 & 0 & 12 & \\
\hline L5 & 16 & 8 & 8 & 0 & & 0 \\
\hline L5-S1 & 10 & 0 & 2 & 8 & 10 & \\
\hline
\end{tabular}


Table 5 Preoperative subarachnoid pressures and intraoperative epidural pressures

\begin{tabular}{lll}
\hline Case & $\begin{array}{l}\text { Subarachnoid } \\
\text { pressure }\left(\mathrm{cm} \mathrm{H}_{2} \mathrm{O}\right)\end{array}$ & $\begin{array}{l}\text { Epidural pressure } \\
\left(\mathrm{cm} \mathrm{H} \mathrm{H}_{2} \mathrm{O}\right)\end{array}$ \\
\hline 1 & 7 & 57 \\
2 & 7 & 65 \\
3 & 15 & 30 \\
4 & 11 & 38 \\
5 & $\mathrm{NA}$ & $\mathrm{NA}$ \\
6 & 13 & 34 \\
7 & $\mathrm{NA}$ & 23 \\
8 & 16 & 38 \\
9 & 13 & 43 \\
10 & $\mathrm{NA}$ & $\mathrm{NA}$ \\
11 & 12 & 62 \\
12 & 12 & 48 \\
13 & 13 & 68 \\
14 & 10 & 33 \\
15 & 12 & 25 \\
16 & 15 & 37 \\
Mean \pm SD & $12.0 \pm 2.8$ & $42.9 \pm 14.8$ \\
\hline NA & 12 &
\end{tabular}

$N A$ not available, $S D$ standard deviation

was categorized as grade 3. Myelography showed tapering of the dural sac at the L3-S1 levels (Fig. 6). CT myelography showed saucerization of the laminae at the L5-S1 level (Fig. 7). Preoperative subarachnoid pressure was $15 \mathrm{~cm} \mathrm{H}_{2} \mathrm{O}$. Laminectomies with LEL resection were performed at L3-S1. Proliferation of EF was recognized. Intraoperatively, epidural pressure was measured at the L4-5 level (Fig. 8a), and was $25 \mathrm{cmH}_{2} \mathrm{O}$

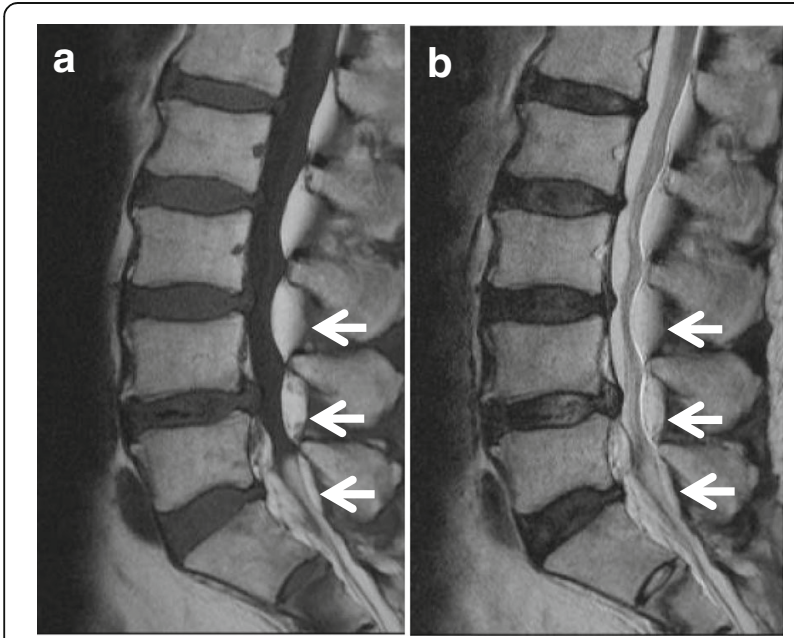

Fig. 4 Lumbar sagittal magnetic resonance imaging. a T1-weighted sagittal image, b T2-weighted sagittal image. Arrows indicate lumbar epidural fat
(Fig. 8b). Symptoms improved immediately after surgery, and the patient was able to walk normally thereafter. At 1 year after surgery, JOA score was 25 and the ratio of recovery was $73 \%$. The histopathological findings consisted of proliferation of mature adipocytes, and LEL was diagnosed.

\section{Discussion}

In this study, clinical courses of patients with LEL were satisfactory after laminectomy. In LEL, epidural pressure increases and symptoms develop through the abnormal proliferation of adipose tissue. The higher epidural pressure induces saucerization of the laminae and/or posterior vertebral body. Furthermore, the direction of proliferative adipose tissue (i.e., site of saucerization) might be related to the types of neurological symptoms.

SEL is a rare disorder characterized by overgrowth of adipose tissue in the extradural space causing compression of the neural elements [2]. This condition is frequently associated with the administration of exogenous steroids or elevation of endogenous steroids [2, 3]. Some cases have emerged without evidence of any clear predisposing factors [6-8]. Most patients with idiopathic SEL are obese [8-10], and more men than women are affected [14]. Steroid-induced SEL has been found to involve the thoracic spine, while idiopathic SEL has been found to predominantly involve the lumbar spine, i.e., LEL [2]. LEL is found in $39-42 \%$ of patients with SEL, and L4-5 is the most commonly involved level [21-23]. Few reports have described cervical SEL [3], and the pathogenesis of SEL has not yet been clarified. Frogel et al. classified SEL into 4 categories: 1) "exogenous steroid use" group, 55.3\%; 2) "obesity only" group, 24.5\%; 3) "endocrinopathy or endogenous steroid" group, 3.2\%; and 4) "non-obese idiopathic" group, approximately $17 \%$ [2]. Four of our patients were consistent with the "exogenous steroid use" group and 12 were in the "obesity only" group. Furthermore, mean BMI was $26.8 \mathrm{~kg} / \mathrm{m}^{2}$ (range, $25.5-27.7 \mathrm{~kg} / \mathrm{m}^{2}$ ), and all 16 patients were overweight.

In patients with LEL, neurological symptoms and signs are similar to degenerative LSS: nonspecific low back pain; radicular pain; numbness and dysesthesias; neurogenic claudication; and CES [12]. In most reported cases, including ours, symptoms show a gradual onset [24, 25] and LEL is sometimes associated with other substantial pathological findings, such as disc herniation and lumbar deformity. The diagnosis of LEL is thus often delayed or missed [26]. In our cases, mean duration of diagnosis was delayed, at 13.1 months.

Imaging criteria for LEL have not been firmly established. CT and myelography do not provide specific findings for LEL, but may be useful as diagnostic support tools. On CT, LEL presents as a homogeneous, hypodense, 


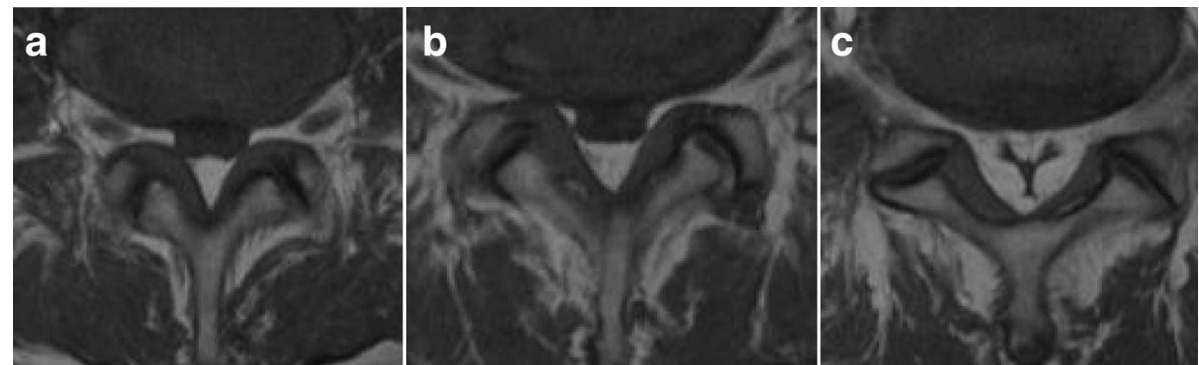

Fig. 5 Lumbar axial magnetic resonance imaging. The adipose tissue compresses the thecal sac at L3-S1 levels, circumferentially. a L3-4 level, $\mathbf{b}$ L4-5 level, c L5-S1 level

epidural mass [27]. Lumbar myelography shows narrowing of the dural sac, which in the absence of bony stenosis on CT myelography indicates an epidural mass [28]. MRI is the most useful diagnostic imaging tool. Borré et al. reviewed the relationship between axial T1-weighted MRI at the L5-S1 level and onset of symptoms in 2258 LEL cases [12]. With regard to the relationship between EF/ SpiC index and onset, symptomatic cases were not seen with Grade I (EF/SpiC, 41-50\%), while symptoms were seen in $14 \%$ of Grade II cases (EF/SpiC, 51-74\%) and all Grade III cases (EF/SpiC, $\geq 75 \%$ ). Kuhn et al. reported the Y-sign as a specific characteristic of LEL on axial T1weighted MRI [14]. In our cases, the Y-sign was recognized in only 7 patients (44\%). Usually, MRI of the spine is performed with basic sequences including T1- and T2weighted sagittal and axial imaging. Because the abnormal accumulation of adipose tissue in the spinal epidural space is shown in LEL, specific sequences such as fat-suppressed T2-weighted imaging might be helpful for differentiation from other epidural lesions [29]. Moreover, diffusionweighted imaging and MR neurography might be useful

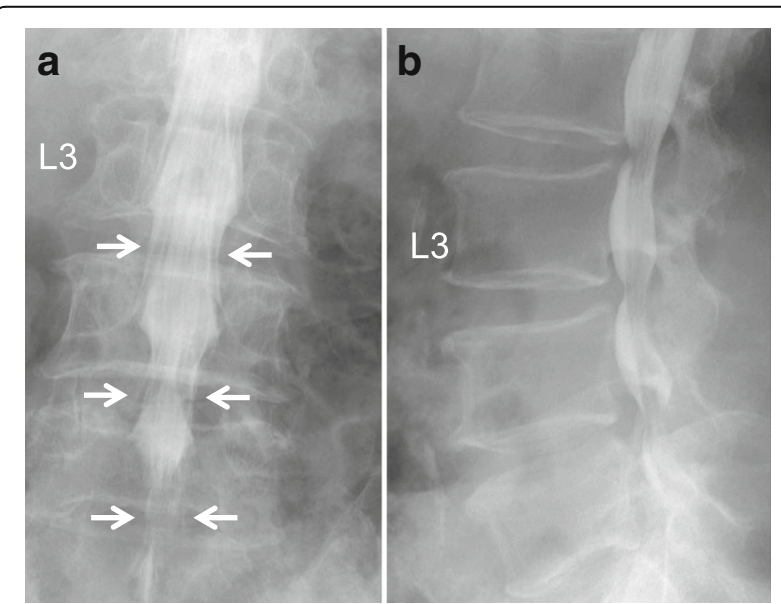

Fig. 6 Myelogram of the lumbar spine. Myelogram shows tapering of the dural sac at the L3 - S1 levels (arrows). a Anterior-posterior view, b lateral view to detect more spinal pathologies and evaluate nerve roots and courses. Further study is necessary on MRI.

Other characteristics of imaging for improved diagnosis of LEL are necessary. To the best of our knowledge, no reports have described CT findings of LEL. The present study clarified saucerization of the laminae and posterior vertebral body on $\mathrm{CT}$ for the first time. In addition, patients in whom CT did not show saucerization of laminae had radicular type, while patients showing saucerization of the posterior vertebral body showed radicular or mixed type. These findings might be useful for the diagnosis and symptoms of LEL.

To the best of our knowledge, no published data on epidural pressures in the spinal canal of LEL patients are available. Barz et al. reported a median epidural pressure of $30.7 \mathrm{cmH}_{2} \mathrm{O}$ at the level of stenosis in LSS [11]. In our study, mean epidural pressure was $42.9 \mathrm{cmH}_{2} \mathrm{O}$ at the L4-5 level in LEL. Epidural pressure was higher in LEL than in LSS. Furthermore, epidural pressure was higher than subarachnoid space pressure in LEL. These findings suggest that the increase in unencapsulated epidural adipose tissue in the spinal canal, which is a closed space, may increase the epidural pressure, and may subsequently lead to the onset of symptoms. The increase in pressure leads to saucerization of the laminae and/or posterior vertebral body. Increased pressure toward the dorsal side (central side) is speculated to lead to saucerization of the laminae, while pressure toward the foraminal side leads to saucerization of the posterior vertebral body. In this study, the site of saucerization was related to subjective symptoms before operation. Specifically, LEL with saucerization of the laminae led to CES, and LEL with saucerization of the posterior vertebral body led to radiculopathy.

Two treatment options for SEL have been recommended: conservative therapy and surgical intervention [24]. No clinical trials have compared outcomes of both modalities, because of the limited number of cases. Conservative treatment with controlled weight loss for obesity and/or reduction of steroids where possible has been reported [10, 27]. Conservative treatment should 


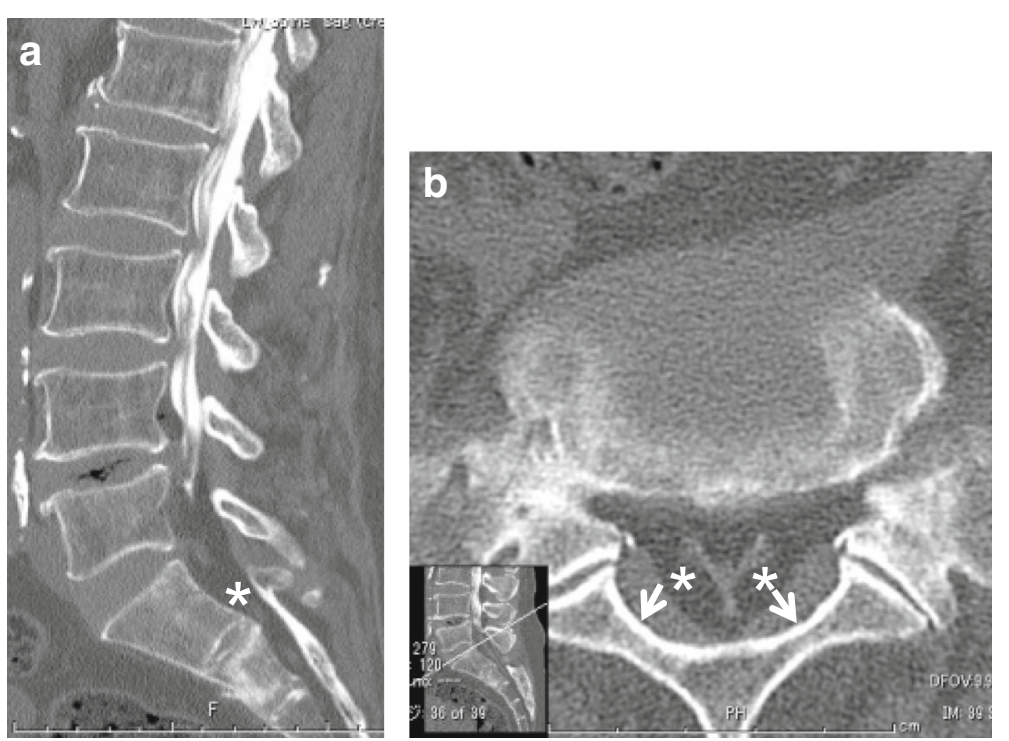

Fig. 7 Computed tomography myelogram. a Reconstructed sagittal view, b axial view. Saucerization of the laminae (arrows) with a homogeneous hypodense epidural mass (asterisks) is shown at the L5-S1 level

be undertaken before surgical intervention. Decompressive surgery with fat resection can be considered when conservative treatment is unsuccessful or when a patient exhibits acute neurological deterioration [25, 26]. Improvement and resolution of the neurological symptoms after surgery have been reported [26]. This study represents one of the largest series of patients with operatively treated symptomatic LEL. Al-Omari et al. reported that no difference between LEL and LSS in terms of operation results such as surgical complications, bleeding during surgery and outcomes [26]. In this study, surgical results were satisfactory during follow-up.
The present study has several limitations. The first limitation is to include LEL with sight LSS. However, all cases satisfied previously reported diagnostic methods $[12,14]$. Furthermore, diagnostic criteria for LEL have yet to be defined. The second limitation was the lack of a control group. Third, the cohort was relatively small and future studies should examine a larger sample.

\section{Conclusions}

In summary, LEL is defined as the abnormal accumulation of unencapsulated adipose tissue in the spinal epidural space, potentially causing various neurological symptoms. Due to the abnormal proliferation of adipose

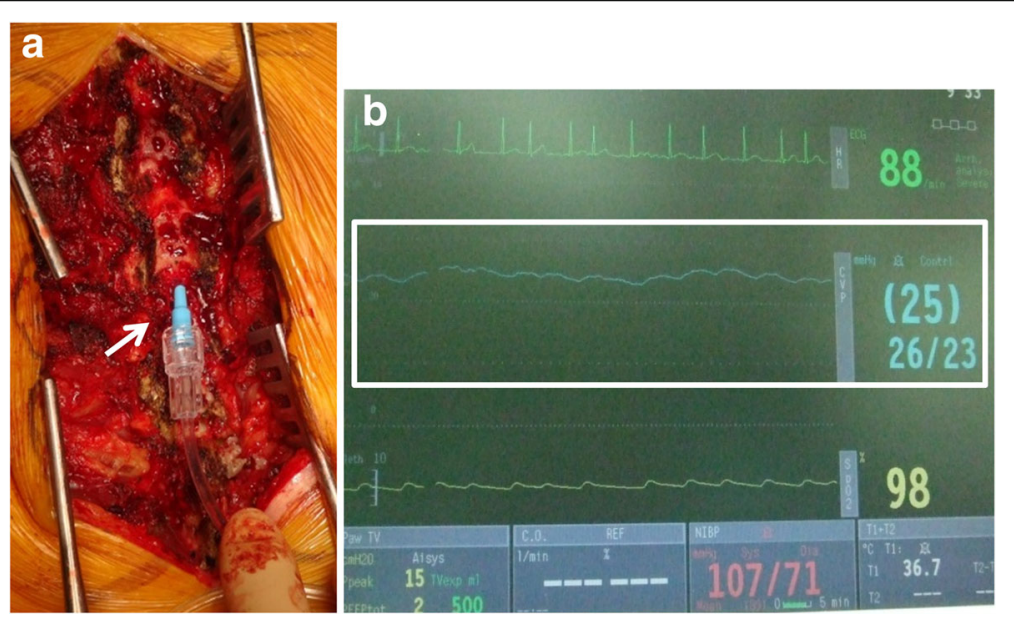

Fig. 8 Intraoperative findings. a Arterial line catheter (arrow) is introduced into the epidural space above the dural sac at an L4-5 interlaminar window. b The epidural pressure shows the fluctuation depending on blood pressure, and it is measured with an average of $25 \mathrm{~mm} \mathrm{H}_{2} \mathrm{O}$ (square) 
tissue, epidural pressure increases and symptoms can develop. Furthermore, the higher epidural pressure results in saucerization of the laminae and/or posterior vertebral body. The direction of proliferation (i.e., site of saucerization) might cause specific symptoms. Future additional studies of larger populations are necessary.

\section{Abbreviations}

ADL: Activities of daily living; A-line: Arterial line; BMD: Body mass index; CES: Cauda equina syndrome; CT: Computed tomography; EF: Epidural fat; i.e.: Id est.; JOA: Japanese Orthopaedic Association; LEL: Lumbar epidural lipomatosis; LSS: Lumbar spinal stenosis; MRI: Magnetic resonance imaging; SD: Standard deviation; SEL: Spinal epidural lipomatosis

\section{Acknowledgements}

We wish to thank Mr. Yoshiki Washizuka (technical assistant, Department of Orthopaedic Surgery) for his secretarial services.

\section{Funding}

This work was supported by Japan Society for the Promotion of Science (JSPS) KAKENHI Grant Number 17 K10961.

\section{Availability of data and materials}

The datasets used and/or analyzed during the current study are available from the corresponding author on reasonable request.

\section{Authors' contributions}

TY and KS made substantial contributions to conception and design. TY and YK were responsible for the acquisition or analysis and interpretation of data. HM and KW provided advice on the data analysis. TY, SS, TH and TRY involved surgical treatment. MK and TK were involved in drafting the manuscript or revising it critically for important intellectual content. TY made a critical revision of the article for important intellectual content. All the authors have read and approved the final manuscript.

\section{Ethics approval and consent to participate}

This report was approved by the Ethics Committee, University of Toyama (Toyama, Japan) and clinical research number "21-22" was granted. All 16 patients provided written consent for publication of this report.

\section{Consent for publication}

Not applicable.

\section{Competing interests}

The authors declare that they have no competing interests.

\section{Publisher's Note}

Springer Nature remains neutral with regard to jurisdictional claims in published maps and institutional affiliations.

\section{Author details \\ ${ }^{1}$ Department of Orthopaedic Surgery, Faculty of Medicine, University of Toyama, 2630 Sugitani, Toyama, Toyama 930-0194, Japan. ²Department of Orthopaedic Surgery, Nippon Koukan Hospital, 1-2-1 Kokandori, Kawasaki, Kanagawa 210-0852, Japan. ${ }^{3}$ Department of Orthopaedic Surgery, Itoigawa General Hospital, 457, Takegahana, Itoigawa, Niigata 941-8502, Japan. ${ }^{4}$ Department of Human Science 1, University of Toyama, 2630 Sugitani, Toyama, Toyama 930-0194, Japan.}

Received: 12 December 2017 Accepted: 23 February 2018 Published online: 01 March 2018

\section{References}

1. Lee M, Lekias J, Gubbay SS, et al. Spinal cord compression by extradural fat after renal transplantation. Med J Aust. 1975;1:201-3.

2. Fogel GR, Cunningham PY 3rd, Esses SI. Spinal epidural lipomatosis: case reports, literature review and meta-analysis. Spine J. 2005;5:202-11.

3. Gupta $R$, Shah $M$, Reese CM. Steroid induced spinal epidural lipomatosiscase report and review of the literature. V Med J. 2011;107:20-2.
4. Sivakumar K, Sheinart K, Lidov M, et al. Symptomatic spinal epidural lipomatosis in a patient with Cushing's disease. Neurology. 1995:45:2281-3.

5. Toshniwal PK, Glick RP. Spinal epidural lipomatosis: report of a case secondary to hypothyroidism and review of literature. J Neurol. 1987:234:172-6.

6. Badami JP, Hinck VC. Symptomatic deposition of epidural fat in a morbidly obese woman. AJNR. 1982;3:664-5.

7. Selmi F, Davies KG, Sharma RR, et al. Idiopathic spinal extradural lipomatosis in a non-obese otherwise healthy man. Br J Neurosurg. 1994;8:355-8.

8. Haddad SF, Hitchon PW, Godersky JC. Idiopathic and glucocorticoidinduced spinal epidural lipomatosis. J Neurosurg. 1991;74:38-42.

9. Fujita N, Hosogane N, Hikata T, et al. Potential involvement of obesityassociated chronic inflammation in the pathogenesis of idiopathic spinal epidural lipomatosis. Spine. 2016;41:E1402-7.

10. Robertson SC, Traynelis VC, Follett KA, et al. Idiopathic spinal epidural lipomatosis. Neurosurgery. 1997;41:68-74.

11. Barz T, Melloh M, Staub LP, et al. Increased intraoperative epidural pressure in lumbar spinal stenosis patients with a positive nerve root sedimentation sign. Eur Spine J. 2014;23:985-90.

12. Borré DG, Borré GE, Aude F, et al. Lumbosacral epidural lipomatosis: MRI grading. Eur Radiol. 2003;13:1709-21.

13. Hierholzer J, Benndorf G, Lehmann T, et al. Epidural lipomatosis: case report and literature review. Neuroradiology. 1996;38:343-8

14. Kuhn MJ, Youssef HT, Swan TL, et al. Lumbar epidural lipomatosis: the "Y" sign of thecal sac compression. Comput Med Imaging Graph. 1994;18:367-72.

15. Quint DJ, Boulos RS, Sanders WP, et al. Epidural lipomatosis. Radiology. 1988;169:485-90.

16. Meyerdyng HW. Spondylolisthesis. Surg Gynec and Obstet. 1932;54:371-7.

17. Konno S, Kikuchi S, Tanaka Y, et al. A diagnostic support tool for lumbar spinal stenosis: a self-administered, self-reported history questionnaire. BMC Musculoskelet Disord. 2007:8:102.

18. Kanamori M, Matsui $\mathrm{H}$, Hirano N, et al. Trumpet laminectomy for lumbar degenerative spinal stenosis. J Spinal Disord. 1993:6:232-7.

19. Yasuda T, Kawaguchi Y, Suzuki K, et al. Five-year follow up results of posterior decompression and fixation surgery for delayed neural disorder associated with osteoporotic vertebral fracture. Medicine. 2007;96:51.

20. Hirabayashi K, Miyakawa J, Satomi K, et al. Operative results and postoperative progression of ossification among patients with ossification of cervical posterior longitudinal ligament. Spine. 1981;6:354-64.

21. Roy-Camille R, Mazel C, Husson JL, et al. Symptomatic spinal epidural lipomatosis induced by a long-term steroid treatment. Review of the literature and report of two additional cases. Spine. 1991;16:1365-71.

22. Kawai M, Udaka F, Nishioka K, et al. A case of idiopathic spinal lipomatosis presented with radicular pain caused by compression with enlarged veins surrounding nerve roots. Acta Neurol Scand. 2002;1058:322-5.

23. Guegan $Y$, Fardoun $R$, Launois $B$, et al. Spinal cord compression by extradural fat after prolonged corticosteroid therapy. J Neurosurg. 1982;56:167-269.

24. Chan JY, Chang CJ, Jeng CM, et al. Idiopathic spinal epidural lipomatosis two cases report and review of literature. Chang Gung Med J. 2009:32:662-7.

25. Ishikawa Y, Shimada Y, Miyakoshi N, et al. Decompression of idiopathic lumbar epidural lipomatosis: diagnostic magnetic resonance imaging evaluation and review of the literature. J Neurosurg Spine. 2006;4:24-30

26. Al-Omari AA, Phukan RD, Leonard DA, et al. Idiopathic spinal epidural lipomatosis in the lumbar spine. Orthopedics. 2016:39:163-8.

27. Pouchot J, Si-Hassen C, Damade R, et al. Cauda equina compression by epidural lipomatosis in obesity. Effectiveness of weight reduction. J Rheumatol. 1995;22:1771-5

28. Payer M, Van Schaeybroeck P, Reverdin A, et al. Idiopathic symptomatic epidural lipomatosis of the lumbar spine. Acta Neurochir. 2003;145:315-20.

29. Kumar Y, Gupta N, Chhabra A, et al. Magnetic resonance imaging of bacterial and tuberculous spondylodiscitis with associated complications and non-infectious spinal pathology mimicking infections: a pictorial review. BMC Musculoskelet Disord. 2017:18:244 